\title{
السلطة الوالدية و أثرها في بناء شخصية الأبناء
}

الأستاذ الدكتور نصر الدين جابر/الأستاذة:سليمة حمودة

كلية العلوم الإنسانية والاجتماعية

جامعة محمد خيضر، بسكرة، الجزائر

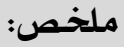

يعتبر موضوع السلطة الوالدية من المواضيع الهامة في التششئة الاجتماعية،

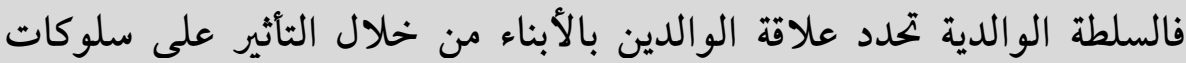

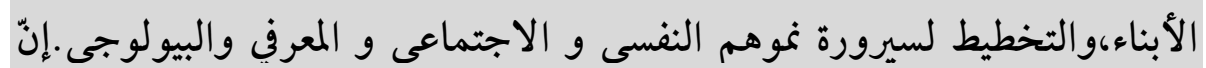

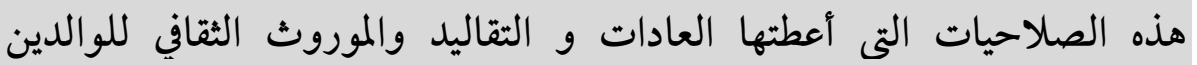

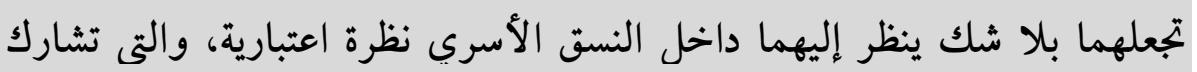
أثار ها في بناء شخصية الأبناء.

\section{Résumé:}

L'autorité parentale est considérée comme l'un des plus important sujet de la socialisation, qui permet de déterminer la relation des parents avec leurs enfants grâce à l'influence sur les comportements des enfants, ainsi que sur le processus de développement psychologique, social, cognitif, biologique .Ces pouvoirs conférés par les coutumes et les traditions et le patrimoine culturel des parents permettant à déterminer la personnalité des enfants. 
تعد الأسرة الوحدة الاجتماعية في توجيه الأبناء وفق قيم المجتمع، فهي

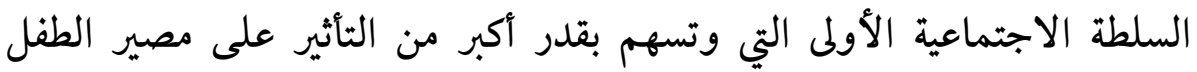

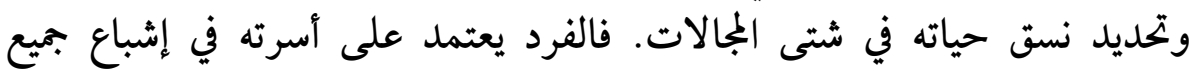

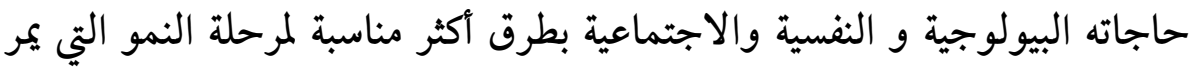

بها.

لقد أكد العديد من علماء النفس و الاجتماع و التربية على الدور الذي الذي الذياء

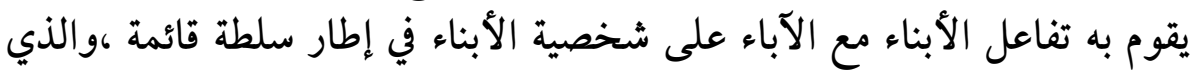

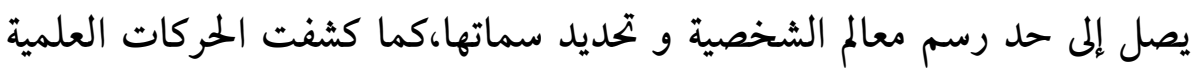
ودراسات الصحة النفسية عن وجود علاقة بين السلطة الوالدية ويين ما يصاب

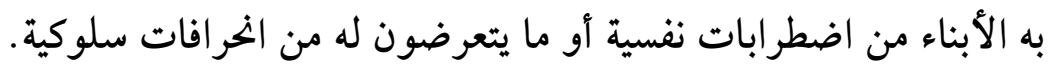

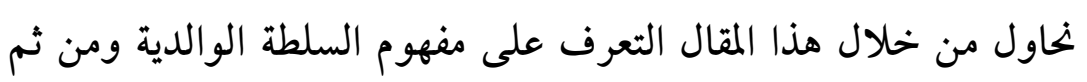
علاقتها ببناء وتحديد شخصية الأبناء

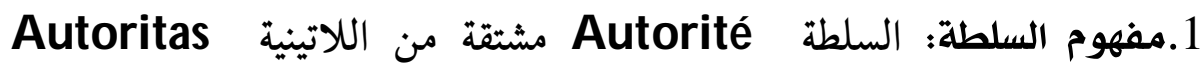

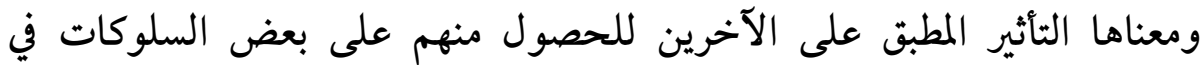
مواقف معينة (1). 1.1 - معنى السلطة لغة: ورد في القاموس المحيط بأنها "القدرة والقوة والقهر." 2.1- في المعجم الفلسفي: هو'السلطان الذي يكون للإنسان على غيره، وهي جهاز اجتماعي يمارس السلطة" (2.).

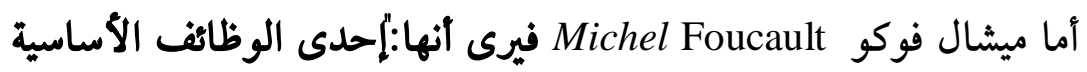

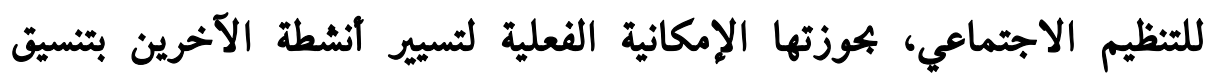
المصالح عن طريق القوة والقسر." 
2) يرى إ.فروم Erich Froom أن "السلطة ليست صفة يملكها الشخص فهي تشير إلى علاقة بين الأشخاص، فيما يتطلع الشخص إلى المالى الآخر على أنه إنسان أعلى منه (3).

3) تو صل ميلغرام (1992, Millgram) في تجاربه حول طاعة السلطة إلى أن: "السلطة هي القوى الاجتماعية المحيطة بالبيئة التي يعيش فيها الفرد وتكون ذات التئي

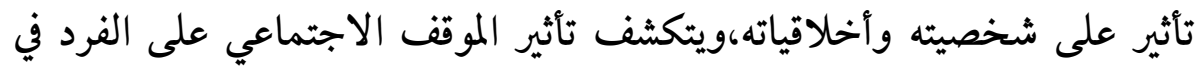
اختلاف الأدوار التي يقوم بهاب(4).

4) أما تانبوم Tannnenbaum: فيعرفها على أنها: "الحق الرسمي الذي يمتلكه إنها

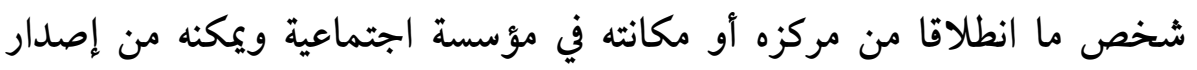
الأوامر للأشخاص الذين هم دونه في المستوى التنظيمي". 5) في حين يرى كل من باركلي وبيتيريلا وجولدنز:أن "السلطة ممارسة للضبط الضيط

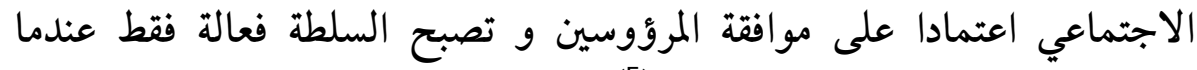
تكون مقبولة من الذين تمارس عليهم (5)،

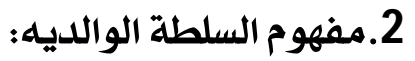

يرجع مفهوم السلطة الوالدية إلى مفهوم السلطة الأبوية المشتقة من الأبنات

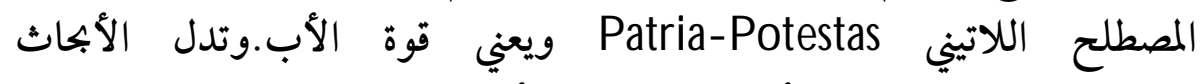

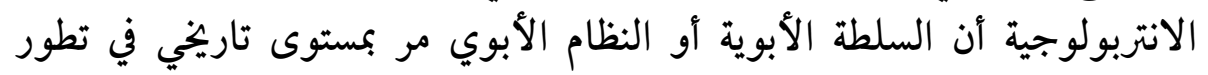

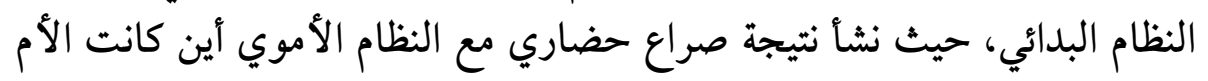

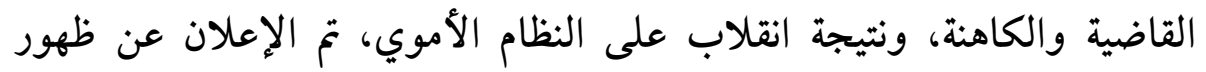

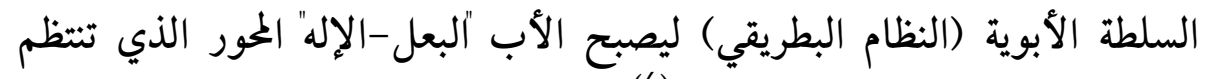
حوله العائلة فهو رب البيت وعموده (6). وسيطرة الأب في العائلة شأنه في المجتمع إذ أن العلاقة بين الأب وأبنائه

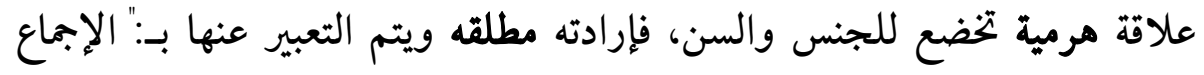




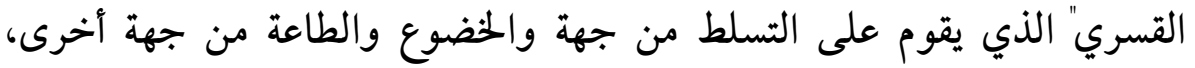

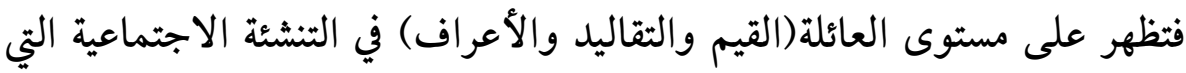

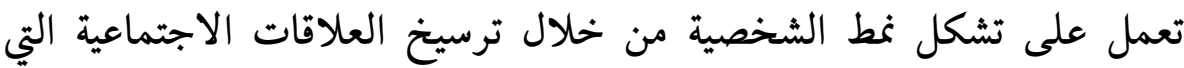
يجتاج إليها المجتمع الأبوي (7).

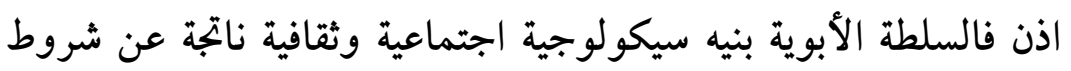

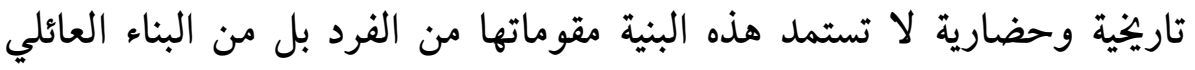

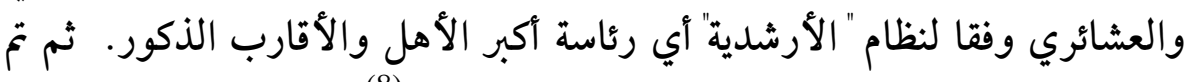

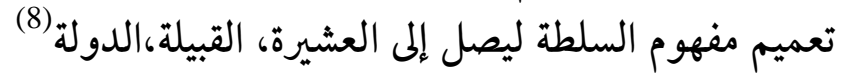
لقد أشار كل من (H.luccioni, J.Sutter) أن " السلطة ضرورية للنمو

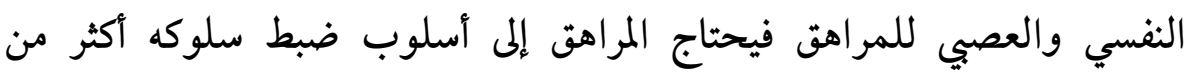
أسلوب العطف والحنان".

وأضاف T.Adorno أن "غياب السلطة الوالدية يعني ممارسة ضعيفة للتنشئة مما

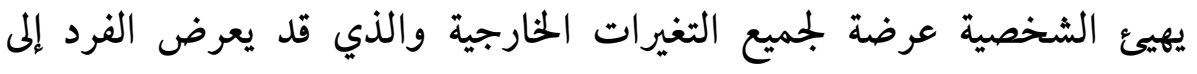

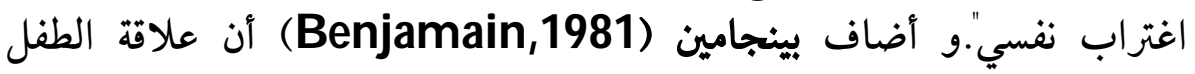
بالسلطة الوالدية تُشيد على أساسين:

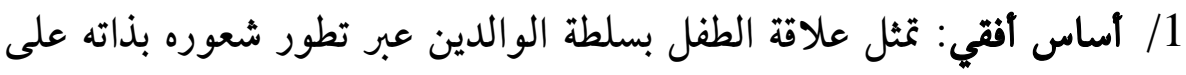

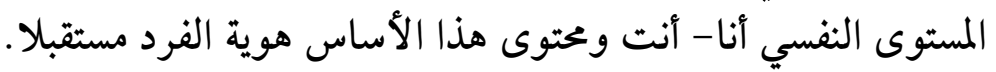
2/ اساس راسي: تمثل الثطور عبر المستوى الاجتماعي وتمثل هوية المجتمع (9).

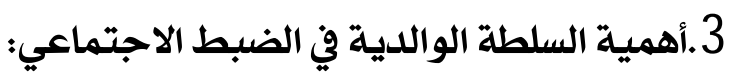
لقد طرح فرويد من خلال كتابه (الأنا والهو،

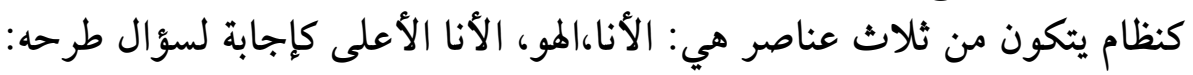

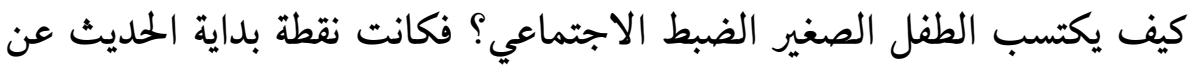


السلطة وتطورها النفسي يكمن في الحديث عن الأنا الأعلى من حيث هو السلطة

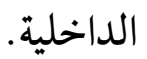

فألانا الأعلى حسب فرويد يعتبر القوانين الأخلاقية التي تشكل نتيجة

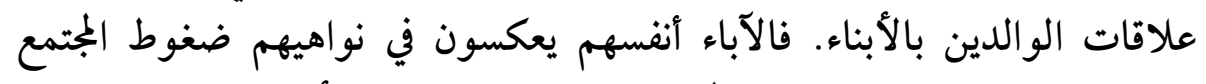

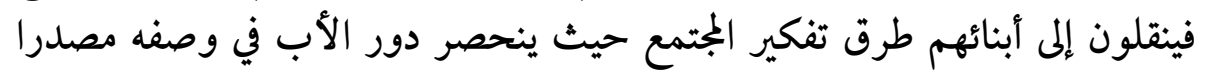

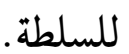

لقد كشفت دراسات التحليل النفسي أن تطور مفهوم السلطة لدى الطفل يمر بمراحل: - n

> المرحلة الأولى (2.1 سنوات) ان الإشباع في هذه المرحلة يعني الحب

$$
\text { والقبول من الأم والجوع يعني الكراهية والرفض. الران. }
$$

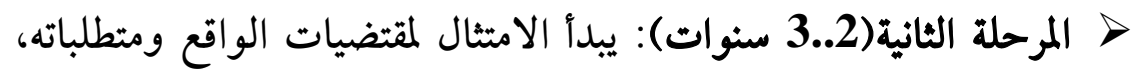

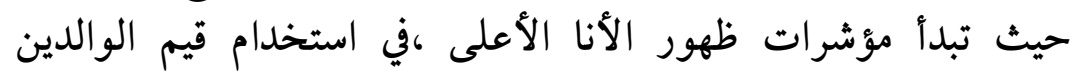
ونو اهيهم وأساليب ضبط السلوك. مؤرات ظكور الانا

> المرحلة الثالثة(5.3 سنوات) يستدخل الطفل قيم الأب ومعاييره لتصبح

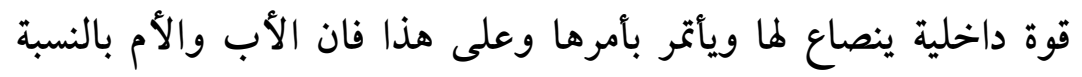

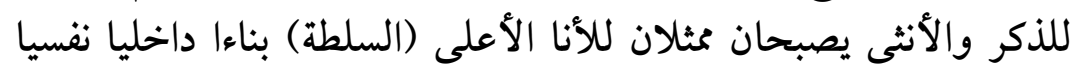

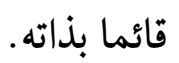

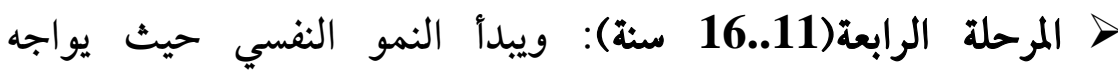

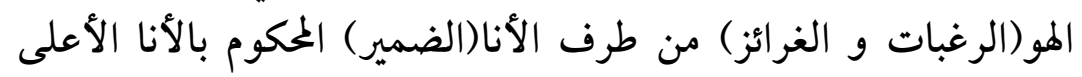

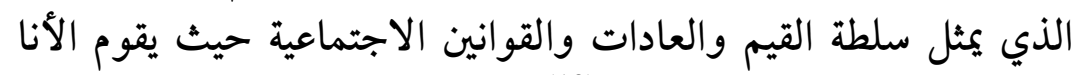

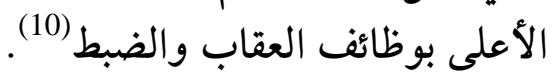

وللتعرف على مراحل تطور الضبط لدى الأطفال،حاول الكثير من علماء النفس دراسته و من أوائل هؤلاء جون بياجيه (J.Piaget,1945) حول 
مراحل النمو الأخلاقي في دراسة تتبعية لأطفال (16.4 سنة) حيث قسم المراحل

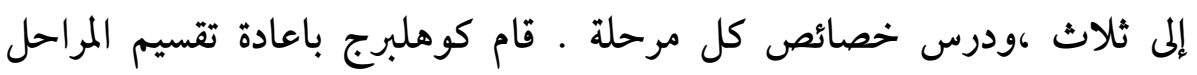

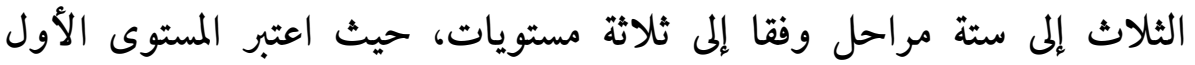

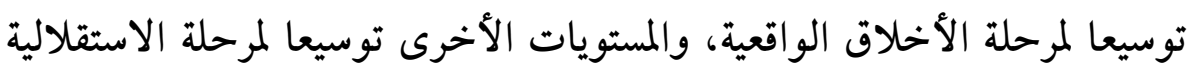

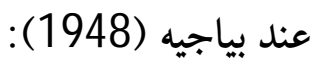

> المرحلة الأولى ( الاتجاه للطاعة و العقاب ): ويتميز تفكير الطفل

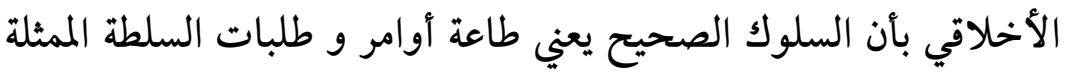

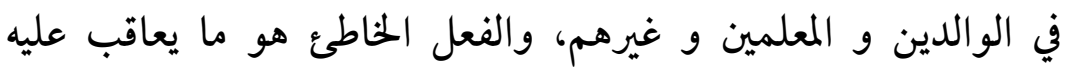

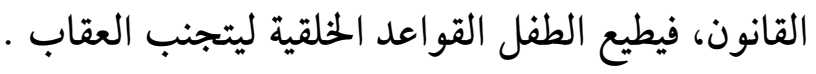

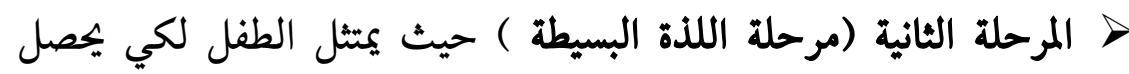

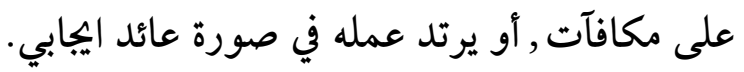
> المرحلة الثالثة ( مرحلة اخحلاق الطفل الجيد ): يسعى الطفل لإقامة

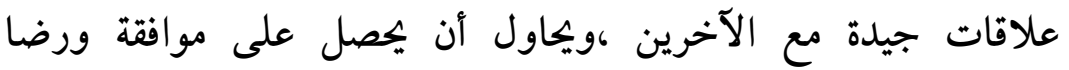

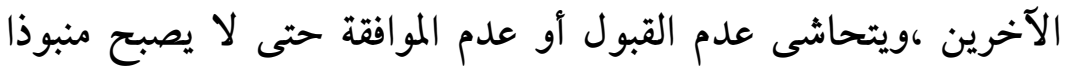

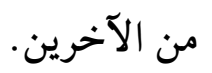

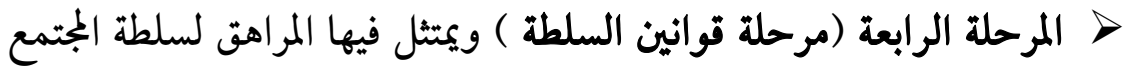

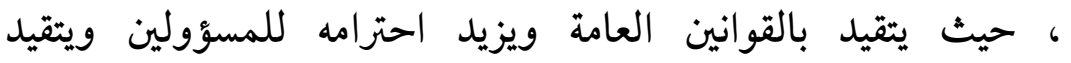
بالواجبات و ذلك من أجل المحافظة على النظام في المجتمع.

المرحلة الخامسة (مرحلة الميثاق الاجتماعي و الحقوق الفردية ): فيبدأ

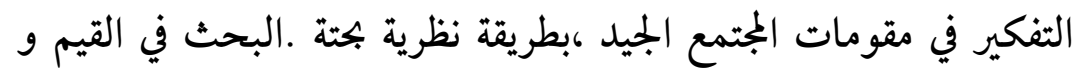
الحقوق و الواجبات.

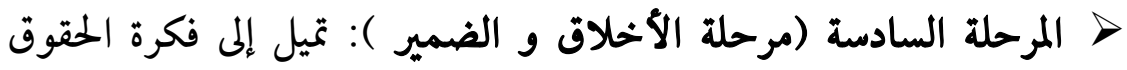

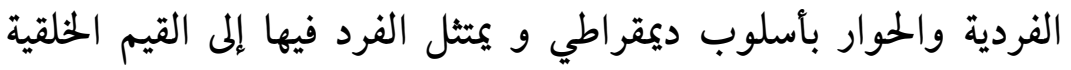




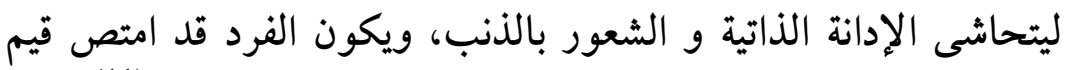

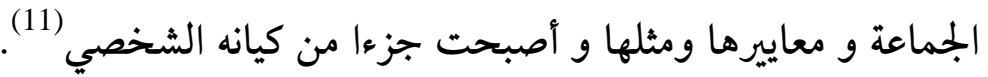

4. السلطة الوالدية وسمات شخصية الأبناء:

لعلاقة الوالدين بالأبناء و اتجاهاتهما نحوه و كيفية التعامل معه تنعكس الإكس

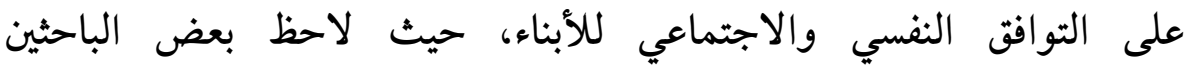

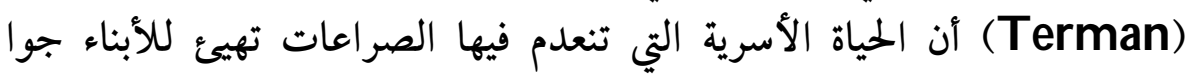

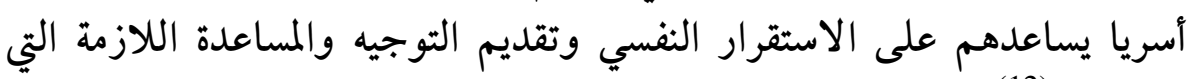

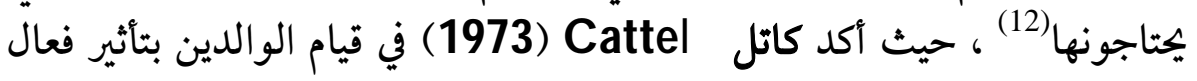

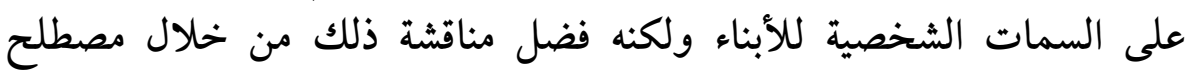

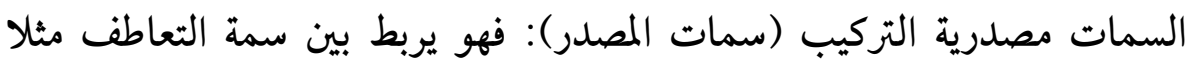

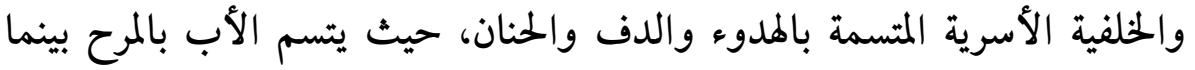

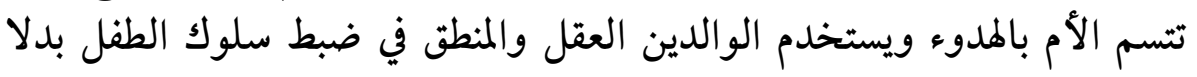

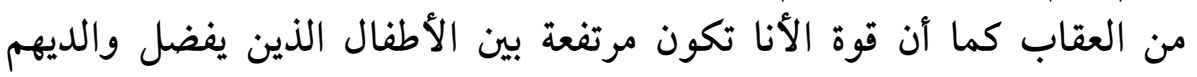

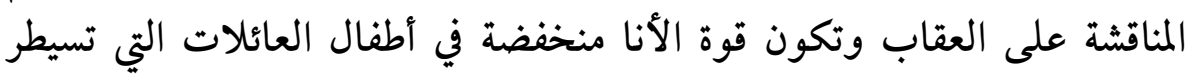

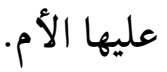

- وأضاف كاتل في عرض بعض الصيّات أن سمة السّيطرة في الأطفال، يتّصف

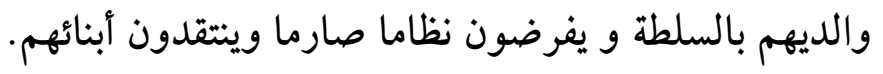

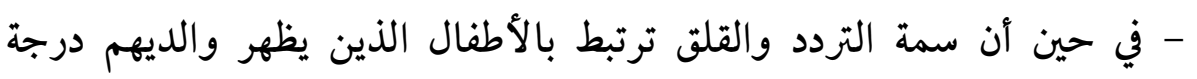

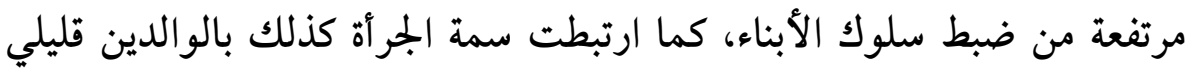

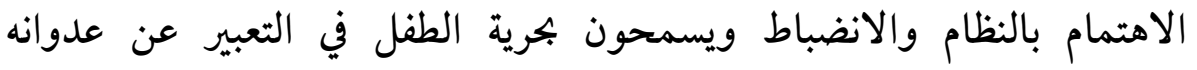
ويستخدمون المنطق بدلا من العقاب. - وسمة الارتياب والشك تتعلق بآباء شغوفين بالمناقشة والجدل. 
- كذلك فإن الأطفال المتصفين بالإفراط في الخيال هروبا من الواقع فلديهم آباء لا الا

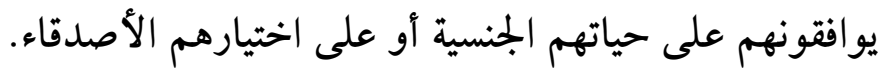

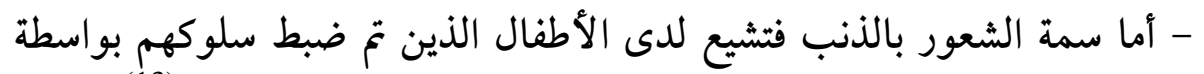

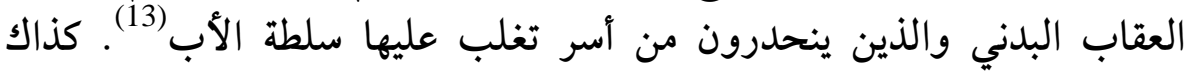

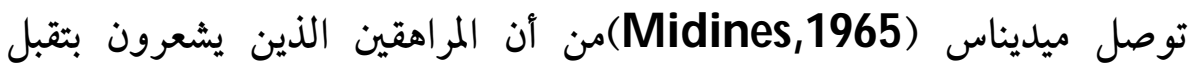

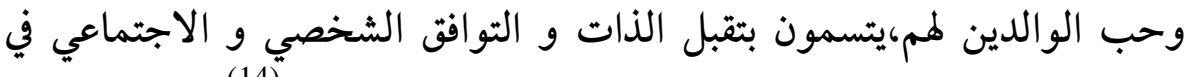

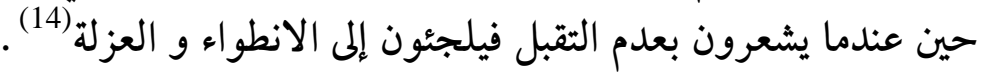

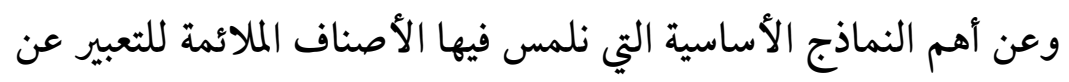

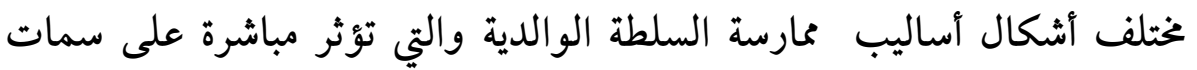

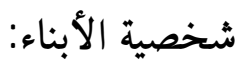

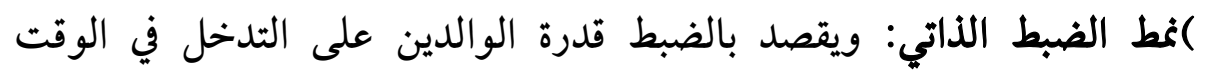

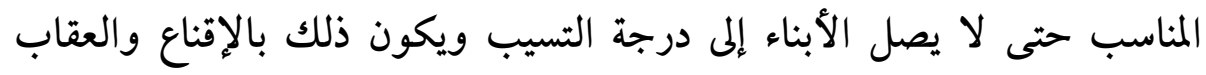

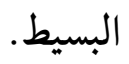

وترى ديانا بوميرنيد أنه يكن للوالدين ضبط سلوك أبنائهم مع إعطاء قدر من إنماء الحرية لهم مما يساعد الأبناء على الشعور بالثقة في أنفسهم واستقلال لهول ذواتهم.

ولقد أشار كل من رونز و توماس Rollin \& Thomes (1975) إلى وجود

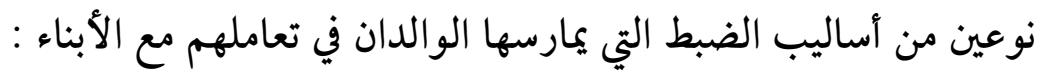

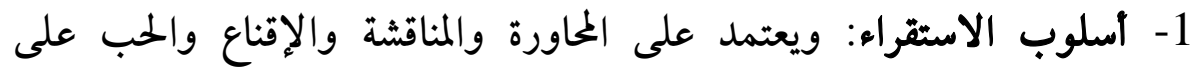

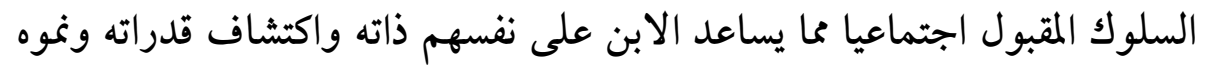

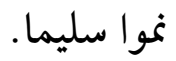
2- أسلوب الإجبار: يعتمد هذا الأسلوب على الإكراه والإجبار على القيام بالسلوك (15). 
2.4)الحماية الزائدة لدى الوالدين: إن الرعاية والاهتمام بالأبناء من الأمور

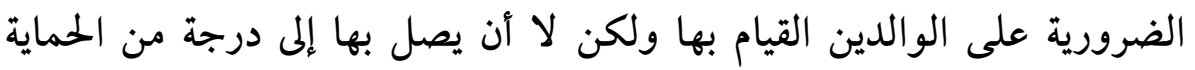

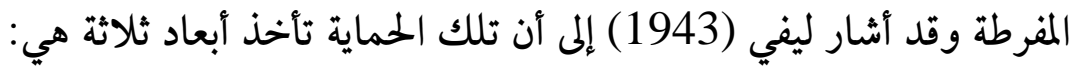
• التعلق المكثف: يتمثل بالحرص على الأبناء الزائد.

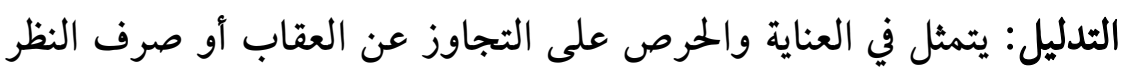
عن تقيم السلوكات الخاطئة.

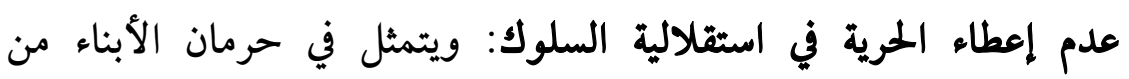

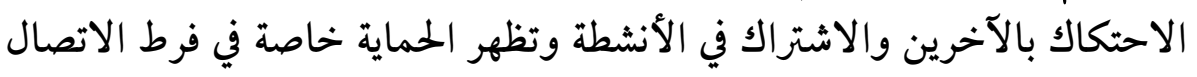

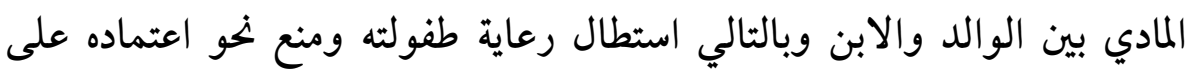

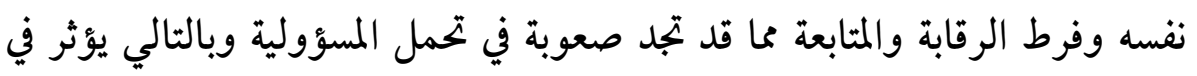
مصدر الضبط لديه.

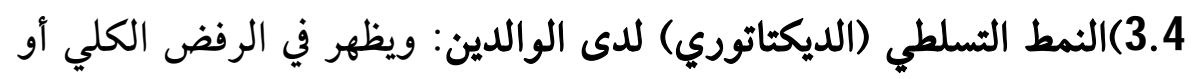

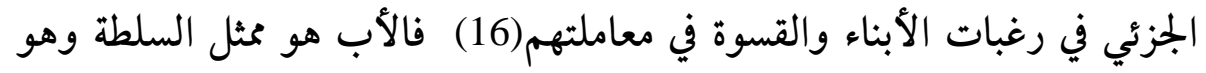

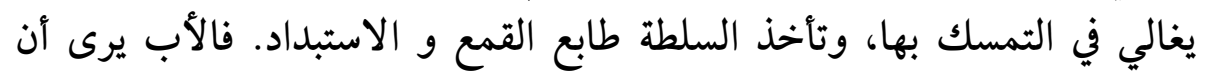

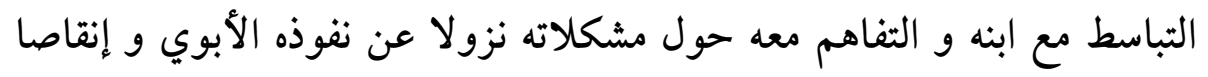

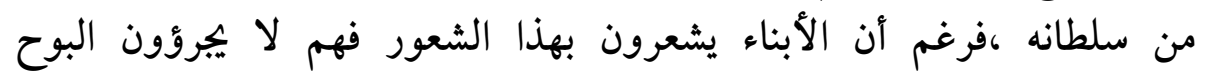
لو الديهم بما يعانونه من مشكلات وآلام ألفاء نفسية: • الشعور بالنقص و عدم الثقة بالنفس و التميز بالخضوع. • الشعور الحاد بالذنب و الانسحاب في بعض الحالات من الحياة الاجتماعية .

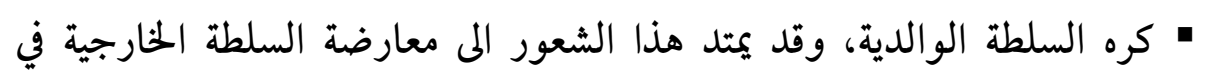

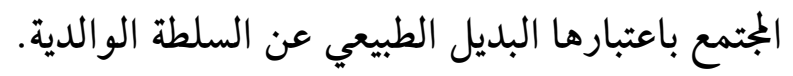

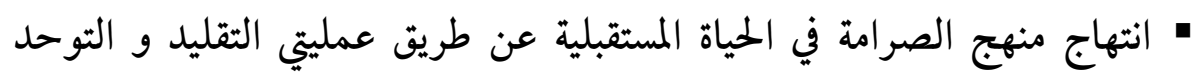
لشخصية أحد الوالدين أو كلاهما. 
5. السلطة الوالدية في الأسرة لجزائريـة:

كانت عملية التنشئة الاجتماعية في الأسرة الجزائرية تتخذ طابعا جماعيا

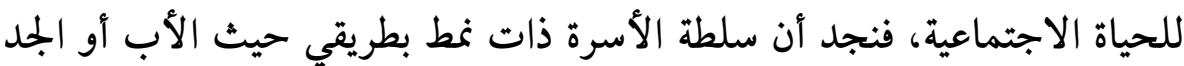

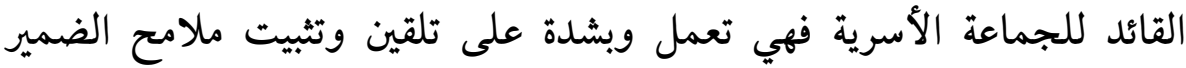

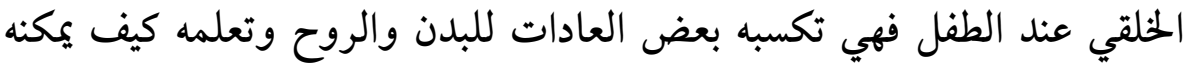
التعامل إزاء الآخرين فالطفل يلاحظ عادات محيطه، ويتعلم السلوكات دون ترنيه ترك

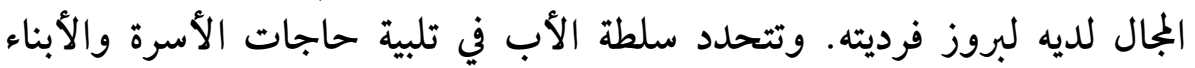

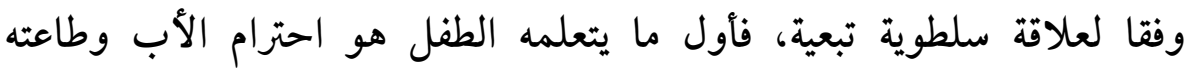

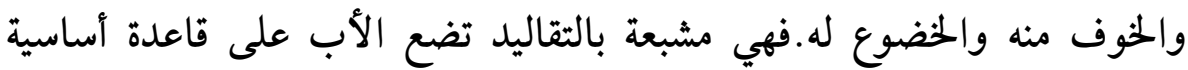

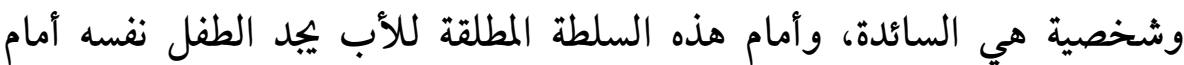
امتثال وخضوع لقوة سلطة الأب ومكانته (18).

فالسلطة الأبوية حسب (مصطفى بوتفنوشت،1984) متأصلة عند كل جزائري محافظ يملك شعورا وراثيا لعملية السيطرة فالتنشئة الاجتماعية التي بوتئيت يتلقاها الطفل من أبيه هي ذات علاقة سلطوية ،فأول ما يتعلمه هو احترامه

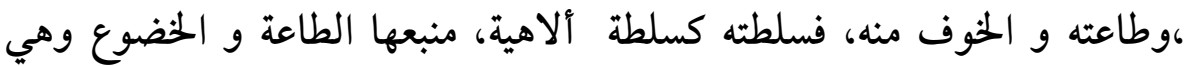

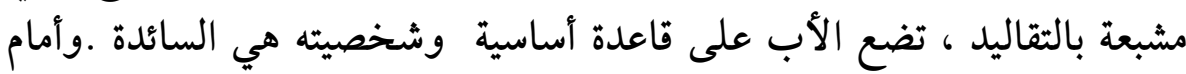

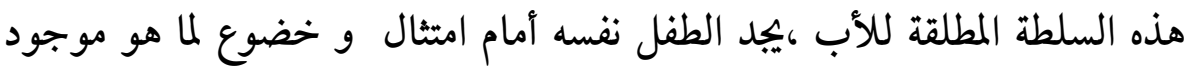

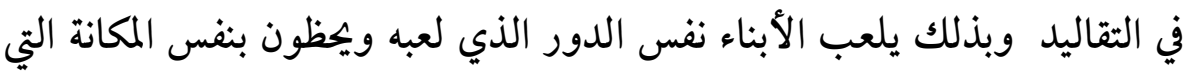

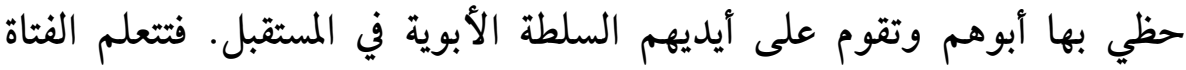
الرضوخ للسلطة، سلطة الأب و الأخ و فيما بعد الزوج و و حتى لسلطة أبنائها، أما

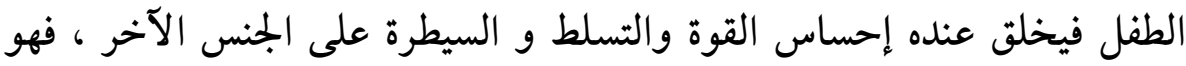

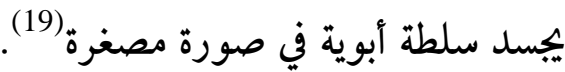


أما عن المرأة في هذا النظام، فتحتل مكانة ثانوية مقارنة بالرجل باعتبار

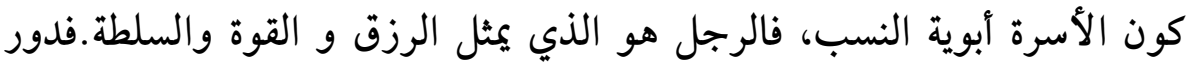

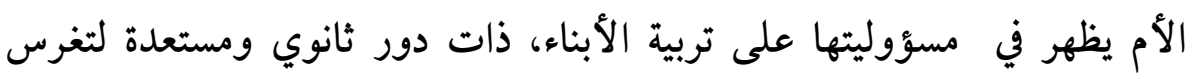

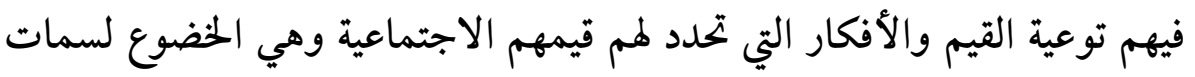

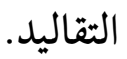

إن النطور الحالي للمجتمع الجزائري أدى إلى انقلاب البيئة الاجتماعية

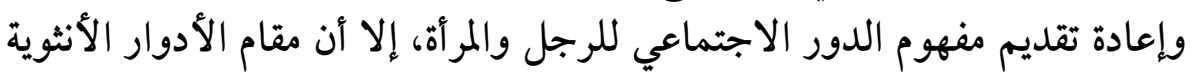

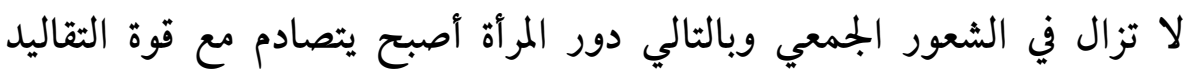

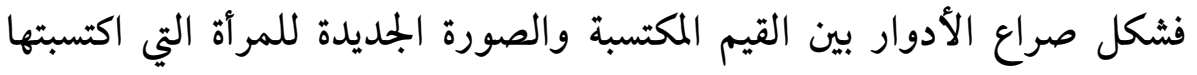
نتيجة للتغير الاجتماعي.

وبذلك تحول التنظيم التقليدي لتوزيع الأدوار الأسرية الذي كان يعطي

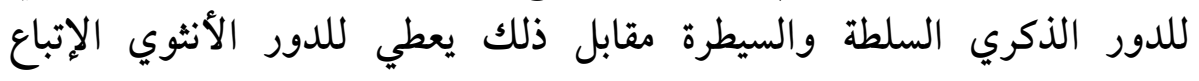

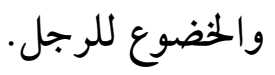

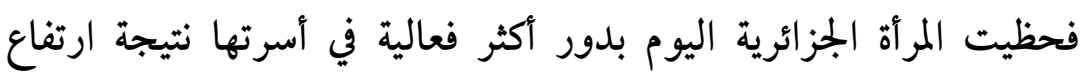

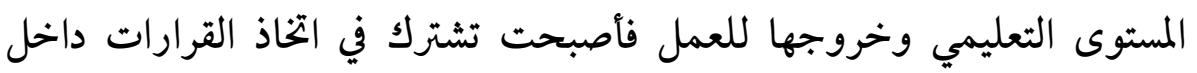

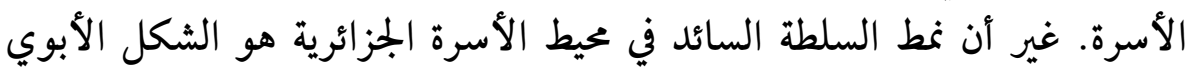

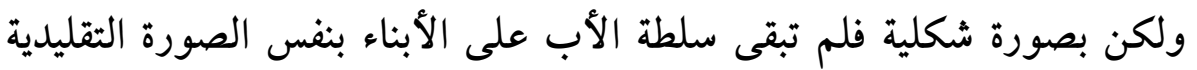

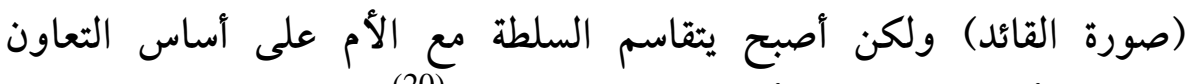
والتكامل أكثر مما تبنى على أساس السلطة والسيادة (20).

ونتيجة للتغيرات التي شهدتها الجزائر على جميع المستويات الثقافة والاقتصادية

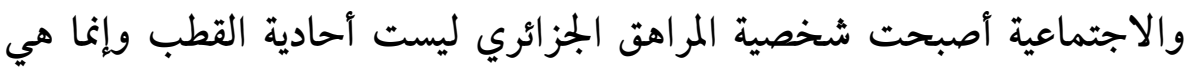

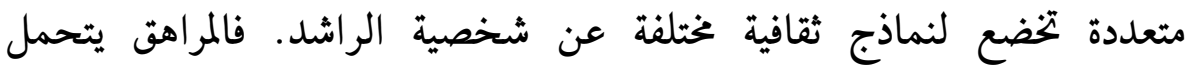

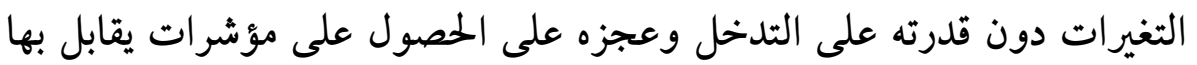

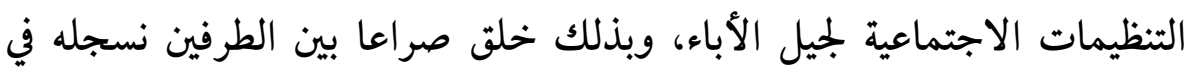


الأسرة باعتبار جيل المراهقين أكثر تفتحا لتيار العصرنة عكس جيل الآباء المحافظ (21).

و لقد أشار كل من سليمان مظهر و عشايبو) S.Medhar \&

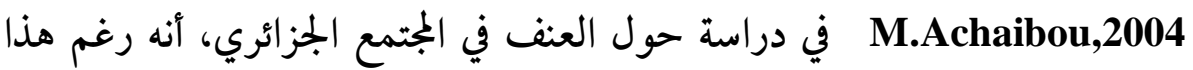
التغير في الأسرة، فإنه تغيير في الأسلوب أكثر ما هو تغيير في المعنى أو المفهوم.

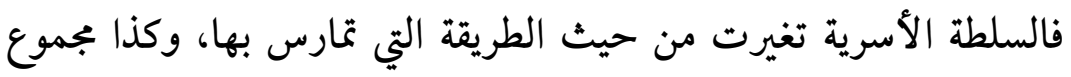

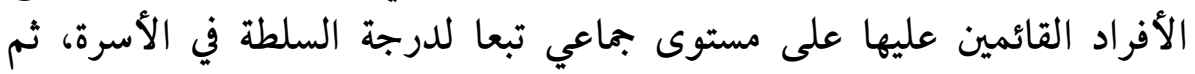

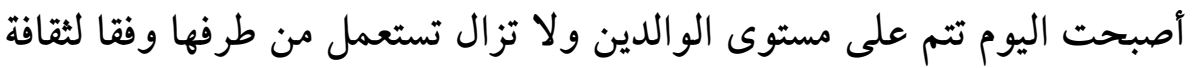

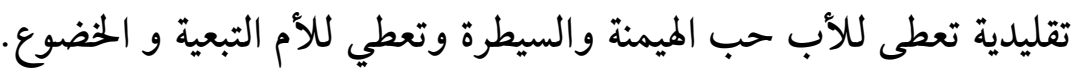

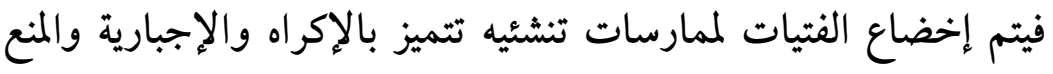

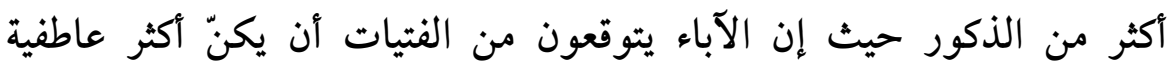
والذكور أكثر فاعلية الذكرو

ونتيجة لهذا تعيش المرأة اليوم تعارضا وجدانيا Ambivalence بين مشاركتها الفعلية في السلطة، وتوجهاتها للعلاقات التقليدية المتسمة بالتسلط

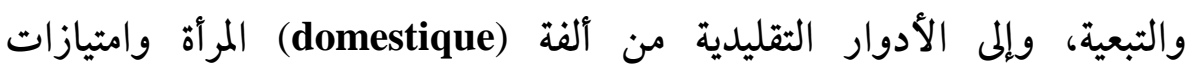

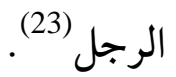

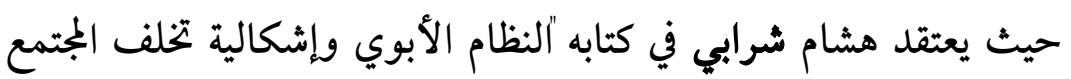

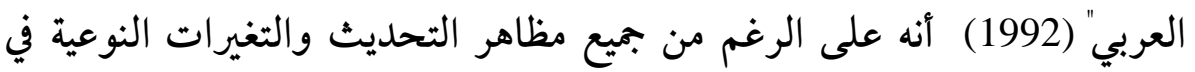

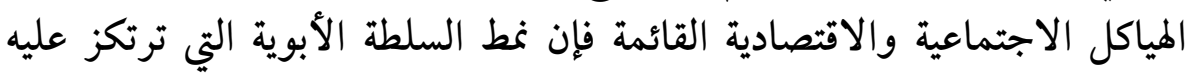

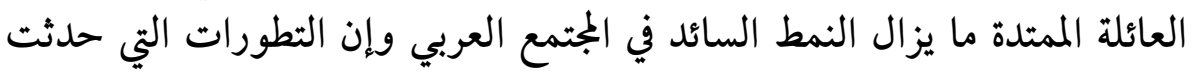

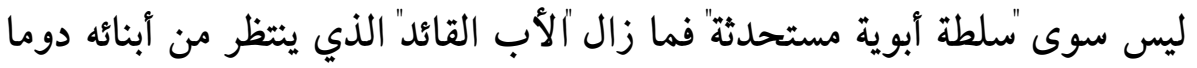
الو لاء المطلق الذي يدفع بالضرورة إلى تضخيم الذكور وتبخيس الإناث (24). 


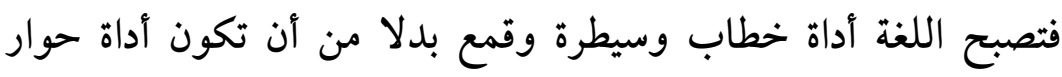

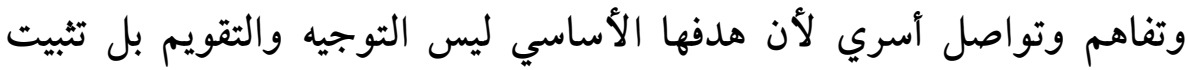
علاقة القوة والسيطرة.

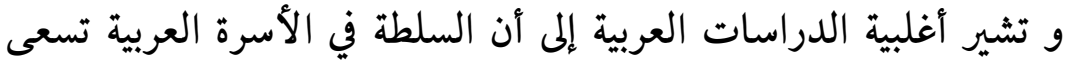

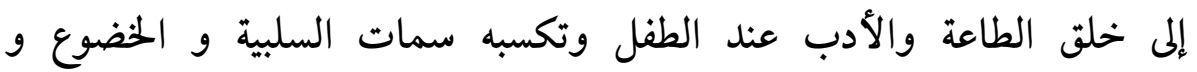

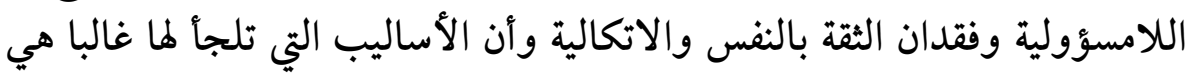

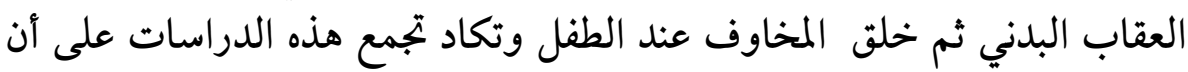

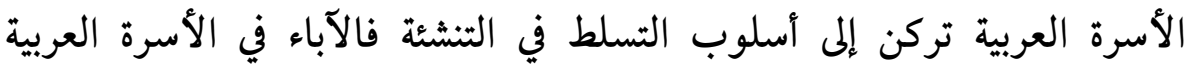

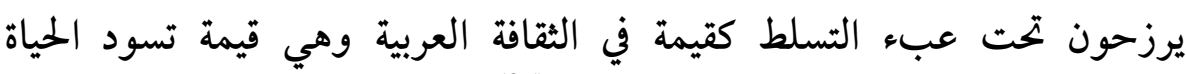

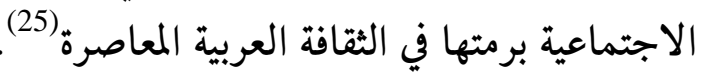

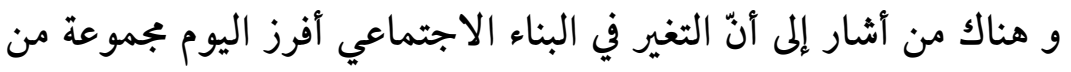

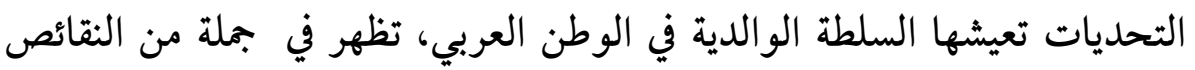

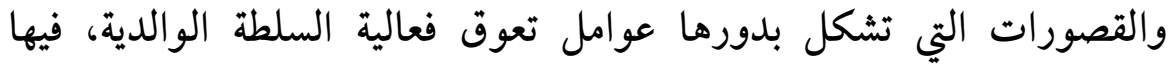

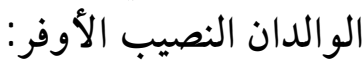

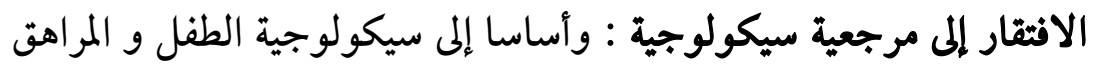
التي تشكل إحدى الركائز القوية .

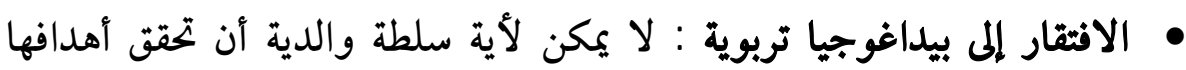

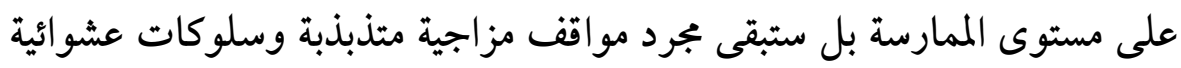
متأرجحة ومعاملات متطرفة ومتناقضة.

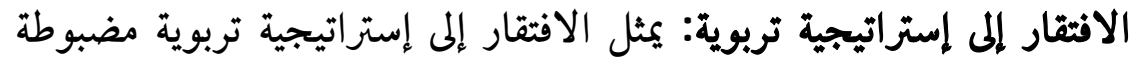

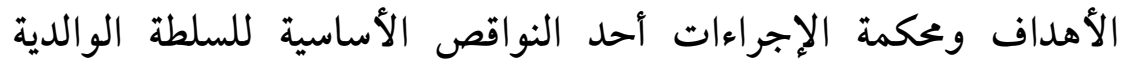

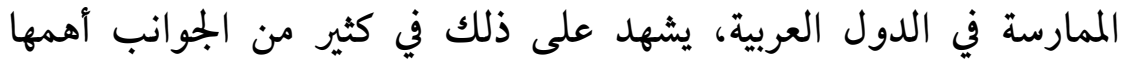

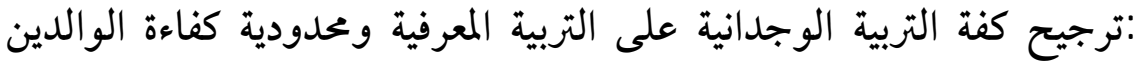
وكذا ضعف الإشراف والتوجيه (26). 
الخاتـمة

تعتبر السلطة الوالدية القاعدة التي تنطلق منها مختلف الأساليب التربوية

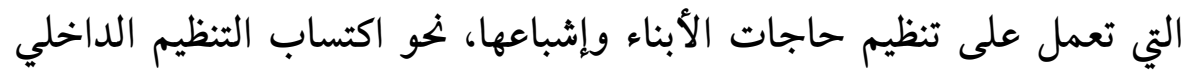

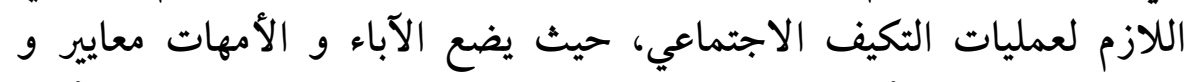

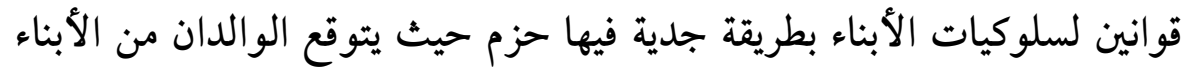

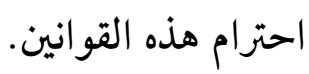

فللسلطة الوالدية الدور الفعال في توجيه الأبناء نحو إتقان مهارات

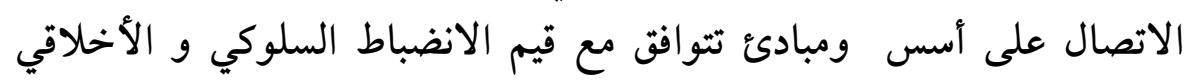

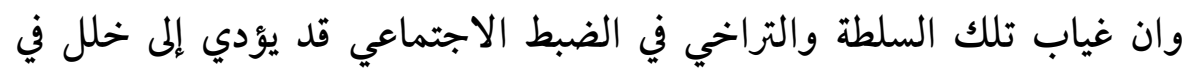

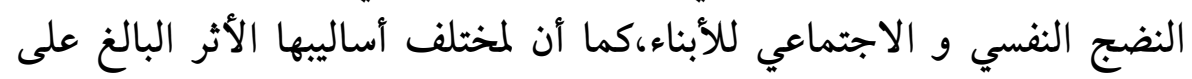
شخصية الأبناء. 


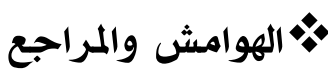

(1) Norbert Sillamy(2003), Dictionnaire de la Psycholologie,Larousse Vol 1.P30.

$$
\text { (2) بجدي عزيز ابراهيم ، (2008)،التربيةوالعولمة، عالم الكتب، القاهرة. }
$$

(3) سلامة محمد عودة (2000)، صورة السلطة و علاقاتها بالتوافق المهني، رسالة ماجستير غير

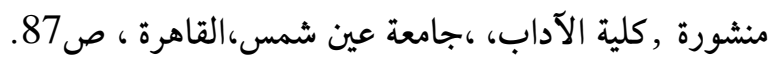

(4) مكلفين روبرت ، رتشارد غروس(2002)،ترجمة ياسمين حداد،مدخل إلى علم النفس الاجتماعي، دار وائل للنشر، عمان ،ص32

(5) الزعيمي مراد (2002)، مؤسسات التنشئة الاجتماعية، منشورات جامعة مختار، عنابة،ص

(6) الجوهري عبد الهادي (2002)، بنية السلطة واشكالية النظام الأبوي في الوطن العربي،

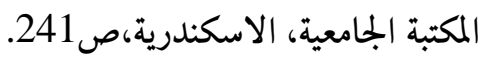

(7) الحيدري إبراهيم ، 2003، النظام الأبوي وإشكالية الجنس عند العرب، داتي الساقي، بيروت ص ص 307، 310

(8) أبو زيد فاروق(2007)،الاعلام و السلطة، عالم الكتب،القاهرة ،ص17.

$$
\text { سلامة محمد عودة (2000)، مرجع سبق ذكره، ص88) }
$$

(10) Andrew-Roberts, Sigmund freud on Personality and society in $\underline{\text { www.index.ac.uk/study/yfrend.html }}$ 22/04/2009

(11) غباري ثائر أحمد ،خالد محمد أبو شعيرة (2009) ، سيكولوجيا النمو الانساني بين

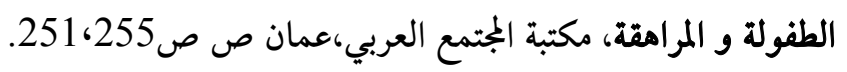

(12) محمد مصطفى زيدان (1990)، النمو النفسي للطفل والمرامق ونظريات الشخصية، ط3، دار الشروق للنشر والتوزيع، جدة، ص ريد 174. 
(13)عبد الرحمان محمد السيد (1998)، نظريات الشخصية، دار قباء للطباعة و النشر

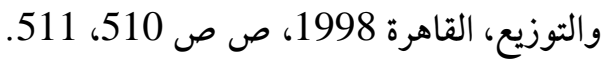

(14) حامد زهران، علم النفس الاجتماعي ، دار المعارف ،مصر، ص 251. (15)عباس محمد عوض و دمنهوري رشاد صالح( 1994)، علم النفس الاجتماعي، نظرياته

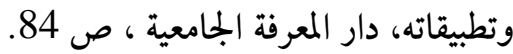

(16)جابر نصر الدين و لوكيا الهاشمي (2006 )، مفاهيم أساسية في علم النفس الاجتماعي،

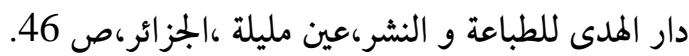

(17) معوض خليل ميخائيل (1981)، دراسة مقارنة في مشكلات المرامقين في الريف و المدينة

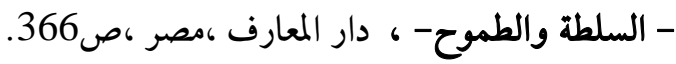

نور الدين تابليت(2007)،المراة بين العمل خارج البيت والتنشثة الاجتماعية للابناء،

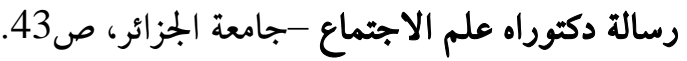

(19) Boutefnouchet. Mohamed (1984), Système social et changement social en Algérie, OPU, Alger, P254.

$$
\text { نور الدين تابليت(2007)،مرجع سبق ذكره، ص56 }
$$

(21) البوراكي، محمد المختار (1987)، السلطة الأبوية في العائلة الجزائرية وحركة التغير دابئ

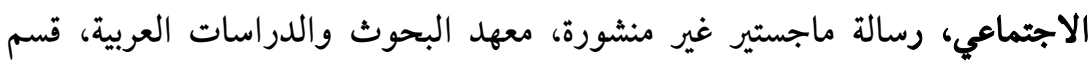

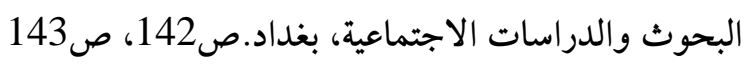

حطب زهير ، مكي عباس (1978)، السلطة الأبوية والثباب: دراسة ميدانية اجتماعية

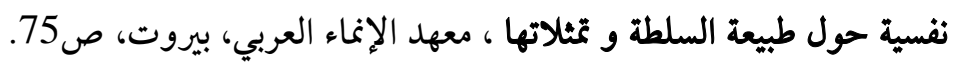

(23) Slimane Madhar et Mahfoud achaibou(2004),étude typologie de la violence à travers la société Algerienne,LRPSO, Alger, PP42,43.

الحيدري إبراهيم ( 2003)، النظام الأبوي وإثكالية الجنس عند العرب، داتي الساقي،

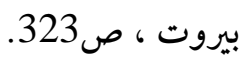


(25) وطفة علي أسعد(1999) ، مظامر التسلط في الثقافة والتربية العربية المعاصرة، بجلة العلوم الإنسانية، جامعة منتوري، عدد الدي 11، 11، قسنطينة.

(26) عبد العزيز بن عثمان التوييي(2001)،التربية الوالدية في العالم الإسلامي، المنظمة فينةد

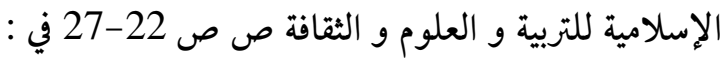

http://www.isesco.org.ma/ara/publication/walidya/page.php 09 /03/2009 
العدد 01 مارس 2012 